\title{
Use of cardiovascular and antidiabetic drugs before and after starting with clozapine versus other antipsychotic drugs
}

Citation for published version (APA):

van der Zalm, Y., Termorshuizen, F., Sommer, I. E., \& Selten, J-P. (2020). Use of cardiovascular and antidiabetic drugs before and after starting with clozapine versus other antipsychotic drugs: a Dutch database study. International Clinical Psychopharmacology, 35(1), 36-41.

https://doi.org/10.1097/YIC.0000000000000292

Document status and date:

Published: 01/01/2020

DOI:

10.1097/YIC.0000000000000292

Document Version:

Publisher's PDF, also known as Version of record

Document license:

Taverne

Please check the document version of this publication:

- A submitted manuscript is the version of the article upon submission and before peer-review. There can be important differences between the submitted version and the official published version of record.

People interested in the research are advised to contact the author for the final version of the publication, or visit the DOI to the publisher's website.

- The final author version and the galley proof are versions of the publication after peer review.

- The final published version features the final layout of the paper including the volume, issue and page numbers.

Link to publication

\footnotetext{
General rights rights.

- You may freely distribute the URL identifying the publication in the public portal. please follow below link for the End User Agreement:

www.umlib.nl/taverne-license

Take down policy

If you believe that this document breaches copyright please contact us at:

repository@maastrichtuniversity.nl

providing details and we will investigate your claim.
}

Copyright and moral rights for the publications made accessible in the public portal are retained by the authors and/or other copyright owners and it is a condition of accessing publications that users recognise and abide by the legal requirements associated with these

- Users may download and print one copy of any publication from the public portal for the purpose of private study or research.

- You may not further distribute the material or use it for any profit-making activity or commercial gain

If the publication is distributed under the terms of Article $25 \mathrm{fa}$ of the Dutch Copyright Act, indicated by the "Taverne" license above, 


\title{
Use of cardiovascular and antidiabetic drugs before and after starting with clozapine versus other antipsychotic drugs: a Dutch database study
}

\author{
Yvonne van der Zalm ${ }^{\mathrm{a}, \mathrm{b}}$, Fabian Termorshuizen ${ }^{\mathrm{a}}$, Iris E. Sommer ${ }^{\mathrm{c}}$ and \\ Jean-Paul Selten ${ }^{\mathrm{a}, \mathrm{b}}$
}

\begin{abstract}
Reports of decreased mortality among patients with schizophrenia who use clozapine may be biased if clozapine is prescribed to relatively healthy patients and if intensive monitoring during its use prevents (undertreatment of) somatic disorder. We aimed to assess whether there is a difference in: (1) somatic comorbidity between patients who start with clozapine and those who start with other antipsychotics and (2) prescribed somatic medication, between patients using clozapine and those using olanzapine. Cohort study based on insurance claims (2010-2015). After selecting new users of antipsychotics and those who subsequently switched to clozapine $(N=158)$, aripiprazole $(N=295)$, olanzapine $(N=204)$ or first-generation antipsychotics $(N=295)$, we compared the clozapine starters to others on cardiovascular or diabetic comorbidity. Those using clozapine and olanzapine were compared on new prescriptions for cardiovascular or antidiabetic drugs. The $\mathrm{OR}_{\text {adj }}$ of cardiovascular or diabetic comorbidity among other starters compared with clozapine starters was 0.77 [95\% confidence interval
\end{abstract}

\section{Introduction}

Although clozapine is the most effective antipsychotic drug for treatment-resistant schizophrenia (Kane et al., 1988; Souza et al., 2013; Siskind et al., 2016), it is also a drug with potentially dangerous side-effects like agranulocytosis, myocarditis and ileus (De Berardis et al., 2018). In addition, its use is associated with more metabolic symptoms [e.g., weight gain, adverse effects on lipid profile and type 2 diabetes mellitus (T2DM)] than other antipsychotics except olanzapine, which has a similar profile of metabolic side-effects (Leucht et al., 2013; Hirsch et al., 2017; Solmi et al., 2017).

Surprisingly, a recent meta-analysis (Vermeulen et al., 2019) found a significantly decreased mortality during clozapine use [mortality rate ratio: 0.56 ; $95 \%$ confidence interval (CI): $0.36-0.85 ; P=0.007)$. However, as we discussed earlier (van der Zalm et al., 2019), the results of this meta-analysis may be biased because the effect

Supplemental Digital Content is available for this article. Direct URL citations appear in the printed text and are provided in the HTML and PDF versions of this article on the journal's website, www.intclinpsychopharm.com.
(Cl): 0.43-1.39], that is, a nonsignificantly increased prevalence associated with clozapine was found. Users of clozapine received significantly more new prescriptions

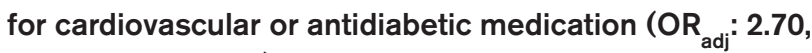
95\% Cl: 1.43-5.08). Starters with clozapine were not cardiovascular/metabolic healthier than starters with other antipsychotics. During its use, they received more somatic treatment. Int Clin Psychopharmacol 35: 36-41 Copyright (c) 2019 Wolters Kluwer Health, Inc. All rights reserved.

\section{International Clinical Psychopharmacology 2019, 35:36-41}

Keywords: clozapine, epidemiology, outpatients, schizophrenia

${ }^{a}$ Rivierduinen Mental Health Institute, Department of Psychosis Research, Leiden ${ }^{b}$ Maastricht University, MHeNS School for Mental Health and Neuroscience, Maastricht and 'University Medical Centre Groningen, Department of Neuroscience and Department of Psychiatry, Groningen, The Netherlands

Correspondence to Yvonne van der Zalm, MSc, Rivierduinen Institute for Mental Health, Sandifortdreef 19, 2333 ZZ Leiden, The Netherlands

Tel: +31 6 11519672; fax: +07 0 4441660; e-mail: y.vanderzalm@rivierduinen.nl

Received 26 March 2019 Accepted 2 October 2019

sizes had not been adjusted for age. Nevertheless, some studies (Tiihonen et al., 2009; Hayes et al., 2015) using age-adjusted effect measures reported a decreased mortality during the use of clozapine compared with the use of other antipsychotics. Considering that schizophrenia shortens life expectancy by more than 20 years (Laursen et al., 2014), it is important to investigate whether clozapine has the potential to increase or decrease this mortality gap and what the mechanism of action is.

A possible explanation for findings of lower mortality during clozapine use is confounding by indication: given its adverse side-effects, physicians may be reluctant to prescribe this drug to patients who have already been diagnosed with (or are at high risk for) cardiovascular disorder or diabetes mellitus. Another explanation is that the intensive monitoring required during the use of clozapine, leads to a more adequate treatment of risk factors for these disorders. For example, weight gain, high blood pressure and increased glucose may be noted and treated more often than during the use of other antipsychotics that do not require weekly or monthly checks. As patients with schizophrenia are in general somatically undertreated (Laursen et al., 2011; Swildens et al., 2016), 
clozapine monitoring may result in better somatic care and thus to a decreased mortality (Kugathasan et al., 2018).

We therefore aimed: (1) to compare cardiovascular and diabetics comorbidity (diagnoses and pertinent medication) between new users of antipsychotics who, after a period of use of a nonclozapine antipsychotic, switch to clozapine, to their counterparts who, after a similar period switch to olanzapine, aripiprazole or first-generation antipsychotics (FGAs) and (2) to determine whether patients are more likely to receive new cardiovascular or antidiabetic drugs during the use of clozapine than during the use of olanzapine. Because olanzapine has similar metabolic effects as clozapine, but does not require weekly or monthly check-ups, it is the comparison drug for question 2.

\section{Methods}

\section{Data source}

For this retrospective cohort study, data from the Achmea Health Insurance Database (AHID) was used. This database of healthcare claims covers over four million subjects in The Netherlands, about $25 \%$ of the population. Insurance for the provision of medical care is compulsory for all Dutch citizens. Health insurance companies are legally obliged to provide citizens with insurance. Therefore, the AHID may be regarded as highly representative for the healthcare utilization of the Dutch population. Besides information on patients characteristics (age and sex), the AHID contains records of every diagnostic and therapeutic provision (so-called diagnosis-treatment-combinations). In the list of all 4391 possible somatic diagnosis-treatment-combinations used by insurance companies, the cardiovascular or diabetic diagnoses were identified by authors F.T. and Y.Z. independently and differences were discussed with author J.-P.S. to reach consensus. The AHID also includes information on all reimbursed drugs. Drug prescriptions during hospitalizations are not registered in this database.

\section{Study cohort and procedures}

The first data-set consisted of all prescriptions of antipsychotic drugs, Anatomical Therapeutic Chemical (ATC) classification code N05A, between 1 January 2010 and 1 January 2016, to patients aged at least 18 years. First, the records for lithium, pipamperon, levomepromazine, periciazine, droperidol and tiapride were removed from this data-set, because in The Netherlands these drugs are mostly prescribed for other indications than schizophrenia or other related psychotic disorders. Second, this database was linked to a database with all insured subjects and we identified all patients who used clozapine, aripiprazole, olanzapine and FGAs during the observation period. We selected these antipsychotics for their similar (olanzapine) or different (aripiprazole and FGAs) profile of metabolic side-effects compared with clozapine.
Third, in an attempt to select patients with a first episode of psychosis, we restricted our analyses to 'new users' of antipsychotics. For this purpose, we selected those who started an antipsychotic after at least one year of no use (a longer period was not desirable since prescribing data of only six years were available). Some of them may have been neuroleptic naive, others may have interrupted their ambulatory treatment for a year or may have been hospitalized for a year (medication use is not registered during hospitalization). Fourth, within this group of new users, we identified patients who were switched to clozapine, aripiprazole, olanzapine and FGAs, after at least 6 months use of nonclozapine antipsychotics. This restriction was necessary because clozapine is a third-line treatment and therefore normally not the drug to start with. In practice, it usually takes at least 6 months to find out that the patient is treatment-resistant. Fifth, patients with records for drugs for Parkinson's Disease (ATC code N04B) or dementia (ATC code N06D) were removed from the cohort, because antipsychotics are regularly prescribed to patients with Parkinson's disease and dementia. Sixth, this database was linked to the database with the somatic diagnosis-treatment-combinations. Patients with a diagnosis of Parkinson's disease or dementia were removed. At last, in order to select only patients with a diagnosis of schizophrenia or other related psychotic disorder, the drug prescription file was linked to a database with codes for psychiatric diagnosis-treatment-combinations (17 codes for different psychiatric disorders).

\section{Statistical analysis}

Descriptive statistics were used to assess baseline characteristics. Clozapine users were compared with users of olanzapine, aripiprazole and FGAs with regard to age (t-test) and $\operatorname{sex}\left(\chi^{2}\right.$ test). To compare cardiovascular and diabetic comorbidity, between patients who start with clozapine and those who start with olanzapine, aripiprazole or FGAs, we performed a logistic regression, adjusting for age and sex. The independent variable was start with clozapine, olanzapine, aripiprazole or FGAs with clozapine as a reference category. The dependent variable was any diagnosis of a cardiovascular disorder or diabetes mellitus type, I or II, or a drug prescribed for these disorders in the four months preceding the start of this antipsychotic drug (yes/no). Our restriction to four months was to ensure that the somatic comorbidity was present and could not be overlooked by the prescribing physician at the moment of starting an antipsychotic. Cardiovascular comorbidity was defined as treatment related to a cardiovascular diagnosis or the use of cardiovascular drugs: ATC codes B01AA, C01, CO2, CO3, C07, C08, C09, C10 (see Supplementary Table S1, supplemental digital content 1, http://links.lww.com/ICP/A67). Diabetic comorbidity was defined as treatment related to a diagnosis of diabetes mellitus or the use of drugs for diabetes: ATC code A10. In addition, we conducted a similar univariate analysis, with olanzapine, aripiprazole and FGAs combined. 
For the second question, as to whether users of clozapine are more likely to receive a prescription for cardiovascular or antidiabetic drugs than users of olanzapine, a cox regression analysis was used. The new users of clozapine and olanzapine were followed (during the use of these drugs) and compared on new use (i.e., no use in the four months preceding the particular antipsychotic) of: (1) cardiovascular drugs and (2) antidiabetic drugs adjusting for age and sex. The follow-up started at the day of the first prescription of either clozapine or olanzapine and ended at the day of the last prescription. An additional logistic regression was performed to assess for differences in proportions of patients who started with cardiovascular or antidiabetic drugs, regardless of the duration of their follow-up period. The cox regression and logistic regression analyses were also performed for all cardiovascular drugs separately. The statistics were performed with SPPS, version 22.0. A two-tailed $P$ value of $<0.05$ was considered statistically significant for all tests.

\section{Ethical approval}

The Executive Board of Achmea gave permission to use their data for this study. Since data had been anonymized, ethical approval was not required.

\section{Results}

\section{Description of cohort}

In the 6-year observation period, 84156 persons were using antipsychotic drugs. See Fig. 1 for a flow diagram. After elimination of those who did not meet the requirement of no antipsychotic use during at least one year and those who were not switched to another antipsychotic after at least 6 months of use, the study population consisted of 952 persons switching to clozapine $(N=158)$, aripiprazole (295), olanzapine (204) or FGAs (295). Their baseline characteristics are shown in Table 1. Given their mean age of over 40 years old, it is unlikely that the cohort only consisted of neuroleptic-naïve patients.

\section{Cardiovascular and diabetic comorbidity at start of antipsychotic treatment}

The results of the logistic regression are shown in Table 2. There were differences in age and sex between the clozapine starters and starters with other antipsychotics in that the olanzapine starters were significantly older than the clozapine starters $(P<0.001)$ and that there were significantly more female aripiprazole starters compared with clozapine starters $(P=0.009)$. After adjusting for age and sex, starters with other antipsychotics had less cardiovascular or diabetic comorbidity than starters with clozapine, although the difference was not statistically significant [odds ratio (OR): 0.77 ; $95 \%$ CI: $0.43-1.39$; $P=0.388)$. The difference between olanzapine-starters and clozapine-starters was smallest $\left(\mathrm{OR}_{\mathrm{adj}} ; 0.92 ; 95 \% \mathrm{CI}\right.$ : $0.46-1.84 ; P=0.818)$.

\section{Cardiovascular and antidiabetic drugs during use of olanzapine and clozapine}

From the 158 starters with clozapine, $13 \mathrm{had}$ a single prescription for such a drug. They were excluded because (as a result of our definition) their duration of follow-up was 0 days. The mean duration of clozapine use for the remaining 145 patients was 487 days (SD 425). From the 204 starters with olanzapine, 30 had a single prescription and were excluded. The remaining 174 patients used olanzapine with a mean duration of 422 days (SD 408). Table 3 shows the results of the Cox regression analysis, adjusting for age and sex. Physicians prescribed significantly earlier cardiovascular drugs (hazard ratio: 2.31; 95\% CI: $1.44-3.69 ; P<0.001)$ to users of clozapine than to users of olanzapine. There was a trend in prescribing antidiabetic drugs to users of clozapine earlier (hazard ratio: 2.53 ; 95\% CI: $1.00-6.39 ; P=0.051$ ). The results of the logistic regression in Table 3 show that cardiovascular or antidiabetic drugs were not only prescribed in an earlier stage, but also more often. Supplementary Table S2, supplemental digital content 1, http://links.lww.com/ ICP/A67 shows that adjusting for cardiovascular/diabetic diagnoses or drugs before the start with clozapine or olanzapine does not change the results.

The differences in cardiovascular drugs were most prominent for 'lipid modifying agents' and 'beta blocking agents', see supplementary Table S1, supplemental digital content 1, http://links.lww.com/ICP/A67. However, after correcting for multiple testing, only 'beta blocking agents' were prescribed significantly earlier to users of clozapine.

\section{Discussion \\ Main findings}

The objective of this study was to examine whether patients who started with clozapine were relatively healthier at the start and better somatically monitored during its use, compared with patients who started with other antipsychotics. The results showed that users of clozapine were not having less cardiovascular or diabetic comorbidity. On the contrary, they seemed to have more cardiovascular or diabetic comorbidity. These findings suggest that confounding by indication is not a likely explanation for lower mortality in clozapine users. However, during the use of clozapine new cardiovascular or antidiabetic drugs were prescribed earlier and more often, compared with those using olanzapine. Although clozapine-users were having more cardiovascular or diabetic diagnoses $(8 \%)$, this difference is small and does not explain the large difference (hazard ratio $>2$ ) in prescribed drugs during the use of clozapine found in this study, see Supplementary Table 2, supplemental digital content 1, http://links.lww.com/ ICP/A67. 


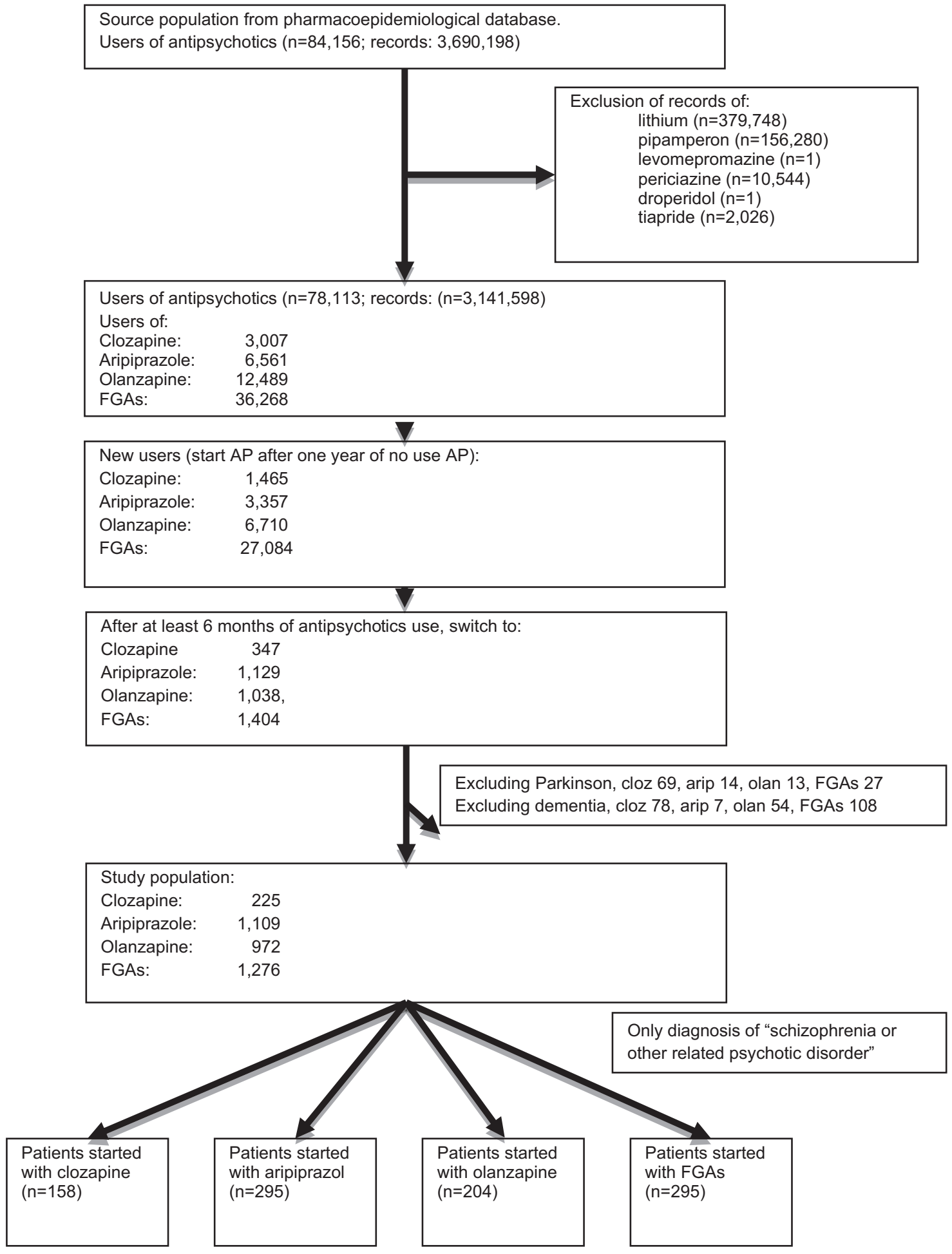

Flowchart.

\section{Interpretation and comparison to other studies}

Our observation that clozapine is not prescribed to relatively healthy patients contradicts findings made in
Canada (Vanasse et al., 2016), but not a report from Denmark (Wimberley et al., 2017). Vanasse et al. (2016) reported that starters with clozapine in Canada were 
Table 1 Baseline characteristics of 952 patients switching to clozapine, aripiprazole, olanzapine or first generation antipsychotics after 1 year of no use of antipsychotics and at least 6 months of other antipsychotic use

\begin{tabular}{|c|c|c|c|c|}
\hline & Clozapine $(N=158)$ & Aripiprazol $(N=295)$ & Olanzapine $(N=204)$ & First-generation antipsychotics $(N=295)$ \\
\hline Age, mean (SD) & $41.7(15.8)$ & $42.5(13.1)$ & $48.9(16.9)$ & $43.7(15.0)$ \\
\hline Sex, male $(\%)$ & $111(70.3)$ & $170(57.6)$ & $122(59.8)$ & $182(61.7)$ \\
\hline Diabetes mellitus diagnosis (\%) & $1(0.6)$ & $5(1.7)$ & $3(1.5)$ & $9(3.1)$ \\
\hline Cardiovascular diagnosis (\%) & $11(7.0)$ & $12(4.1)$ & $17(8.3)$ & $11(3.7)$ \\
\hline Drugs for diabetes, without diagnosis (\%) & 0 & 0 & 0 & $2(0.7)$ \\
\hline Cardiovascular drugs, without diagnosis (\%) & $4(2.5)$ & $3(1.0)$ & $4(2.0)$ & $5(1.7)$ \\
\hline
\end{tabular}

Table 2 Results of a logistic regression, comparing starters with aripiprazole, olanzapine and first generation antipsychotics to starters with clozapine (reference) on cardiovascular and diabetic comorbidity

\begin{tabular}{|c|c|c|c|c|c|c|}
\hline & Crude OR & $95 \% \mathrm{Cl}$ & $P$ value & Adj. $\mathrm{OR}^{\mathrm{a}}$ & $95 \% \mathrm{Cl}$ & $P$ value \\
\hline Aripiprazol & 0.58 & $0.29-1.17$ & 0.125 & 0.58 & $0.28-1.19$ & 0.138 \\
\hline Olanzapine & 1.18 & $0.61-2.31$ & 0.622 & 0.92 & $0.46-1.84$ & 0.818 \\
\hline FGAs & 0.89 & $0.47-1.71$ & 0.736 & 0.85 & $0.44-1.64$ & 0.619 \\
\hline Aripiprazol, olanzapine and FGAs combined & 0.85 & $0.48-1.50$ & 0.563 & 0.77 & $0.43-1.39$ & 0.388 \\
\hline
\end{tabular}

$\mathrm{Cl}$, confidence interval; FGAs, first-generation antipsychotics; OR, odds ratio.

${ }^{a}$ Adjusted for age and sex.

Table 3 Results of a cox regression and a logistic regression comparing starters with clozapine to starters with olanzapine on new cardiovascular and diabetic drugs during the use of clozapine or olanzapine

\begin{tabular}{|c|c|c|c|c|c|c|c|c|}
\hline Cox regression & Clozapine $(N=145)$ & Olanzapine $(N=174)$ & Hazard ratio $^{a}$ & $95 \% \mathrm{Cl}$ & $P$ value & $\mathrm{OR}^{\mathrm{a}}$ & $95 \% \mathrm{Cl}$ & $P$ value \\
\hline Antidiabetes drugs $(N=20)$ & 12 & 8 & 2.53 & $1.00-6.39$ & 0.051 & 2.51 & $0.96-6.60$ & 0.062 \\
\hline Cardiovascular drugs $(N=76)$ & 37 & 39 & 2.31 & $1.44-3.69$ & $<0.001$ & 2.73 & $1.41-5.27$ & 0.003 \\
\hline Total $(N=81)$ & 40 & 41 & 2.38 & $1.51-3.76$ & $<0.001$ & 2.70 & $1.43-5.08$ & 0.002 \\
\hline
\end{tabular}

$\mathrm{Cl}$, confidence interval; OR, odds ratio.

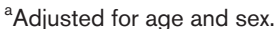

physically healthier compared with starters with other antipsychotics (only $10.8 \%$ had a comorbidity index of 1 or higher, compared with $23.9 \%$ for users of other antipsychotics. Wimberley et al. (2017), however, using the same comorbidity index, found a proportion of $16.3 \%$ among the clozapine starters with a score of 1 or higher, which was not very different from starters with other antipsychotics $(17.3 \%)$. The differences in prescription rates between countries may result in differences in cautiousness regarding prescribing clozapine. To illustrate this, the prescription rates in Canada were very low (1.7\%), whereas in Denmark $57.9 \%$ of the treatment-resistant patients were using clozapine. Assuming the prevalence of treatment resistance is about $30 \%$, the prescription rate in Denmark is about 15\%. In The Netherlands prescription rates are relatively high (21.6\%) (van der Zalm et al., 2018), which may explain the less restrictive use in patients with somatic comorbidity.

There are as yet no studies on the effect of better somatic monitoring in patients using clozapine. Hayes et al. (2015) reported that those prescribed clozapine had more faceto-face clinical contact compared to those not prescribed clozapine, but they did not provide information on the prescription of somatic drugs.

The differences between users of clozapine and users of olanzapine in somatic treatment in our study were most prominent in the following categories of drugs: 'drugs for diabetes', 'beta blocking agents' and 'lipid modifying agents' (statins).

Drugs for diabetes are prescribed in (the beginning of) diabetes, but are also effective to prevent weight gain (de Silva et al., 2016). As shown by Leucht (2013), olanzapine causes more weight gain than any other antipsychotic, but the difference with clozapine was non-significant. Studies have also failed to show a significant difference in the risk for T2DM between users of clozapine and users of olanzapine (Komossa et al., 2010; Jesus et al., 2015; Hirsch et al., 2017; Solmi et al., 2017). Therefore, the difference in prescription of anti-diabetic drugs is not likely to be explained by differences in risk of weight gain or T2DM.

Beta-blocking agents are mostly prescribed for high blood pressure. Clozapine and olanzapine can cause both hypotension and hypertension and no differences between these two agents have been found in this respect (Kelly et al., 2014). However, clozapine is also known to cause tachycardia (Miller, 2000), especially in the initiation phase. The difference between clozapine and olanzapine in prescriptions of beta-blocking agents may therefore be caused to a certain extent by the higher risk of tachycardia associated with the use of clozapine.

Previous studies have shown that the proportions of patients with high LDL cholesterol and triglycerides rates among users of olanzapine and clozapine are similar 
(30-40\%) (Birkenaes et al., 2008). Our result of lipid modifying agents in $12.6 \%$ of olanzapine-users and $14.5 \%$ for clozapine-users confirms the undertreatment earlier mentioned. The more than two-fold increased odds of receiving lipid modifying agents among users of clozapine emerged after adjustment for age.

\section{Strengths and limitations}

To our knowledge, this is the first study to investigate whether patients using clozapine receive better physical healthcare. A strength of this study is the large representative database consisting of almost a fourth of the Dutch population.

There are limitations that need to be addressed. First, because the register did not provide DSM-IV or ICDdiagnoses, but so-called diagnosis-treatment-combinations, we could only use the less specific term 'schizophrenia or other related psychotic disorders'. Second, BMI, blood glucose and dose of prescribed antipsychotic were not available, making it impossible to compare number and severity of metabolic side-effects between different groups. Third, other important variables like duration of illness or duration of untreated illness were not available too. Fourth, reasons for prescribing clozapine were unknown. We only included patients with a diagnosis of schizophrenia or other related psychotic disorder, but there might have been patients for whom the diagnosis was reconsidered and changed into bipolar disorder at a later stage. Finally, an unknown proportion of the 'new users' of antipsychotics in our study were not neuroleptic-naive. A part of them may have used antipsychotics in the past and interrupted their ambulatory treatment for more than a year. Another small part of these 'new users' may have started outpatient antipsychotic use after at least a year of in-patient stay (which is not recorded in the database). However, to answer the questions in our study, patients do not necessarily have to be neuroleptic-naive.

\section{Conclusion}

We found that clozapine is not prescribed to relatively healthy patients. The more frequent prescription of cardiovascular and antidiabetic drugs to patients using clozapine (vs olanzapine) may be the result of more adequate somatic treatment. This is an important finding as it suggests that regular check-ups for psychotic patients may improve somatic care and could help decrease mortality.

\section{Acknowledgements Conflicts of interest}

There are no conflicts of interest.

\section{References}

Birkenaes AB, Birkeland KI, Engh JA, Faerden A, Jonsdottir H, Ringen PA, et al. (2008). Dyslipidemia independent of body mass in antipsychotic-treated patients under real-life conditions. J Clin Psychopharmacol 28:132-137.
De Berardis D, Rapini G, Olivieri L, Di Nicola D, Tomasetti C, Valchera A, et al. (2018). Safety of antipsychotics for the treatment of schizophrenia: a focus on the adverse effects of clozapine. Ther Adv Drug Saf 9:237-256.

de Silva VA, Suraweera C, Ratnatunga SS, Dayabandara M, Wanniarachchi N, Hanwella R (2016). Metformin in prevention and treatment of antipsychotic induced weight gain: a systematic review and meta-analysis. BMC Psychiatry 16:341.

Hayes RD, Downs J, Chang CK, Jackson RG, Shetty H, Broadbent M, et al. (2015). The effect of clozapine on premature mortality: an assessment of clinical monitoring and other potential confounders. Schizophr Bull 41:644-655.

Hirsch L, Yang J, Bresee L, Jette N, Patten S, Pringsheim T (2017). Secondgeneration antipsychotics and metabolic side effects: a systematic review of population-based studies. Drug Saf 40:771-781.

Jesus C, Jesus I, Agius M (2015). What evidence is there to show which antipsychotics are more diabetogenic than others? Psychiatr Danub 27 (Suppl 1):S423-S428.

Kane J, Honigfeld G, Singer J, Meltzer H (1988). Clozapine for the treatment-resistant schizophrenic. A double-blind comparison with chlorpromazine. Arch Gen Psychiatry 45:789-796.

Kelly AC, Sheitman BB, Hamer RM, Rhyne DC, Reed RM, Graham KA, et al. (2014). A naturalistic comparison of the long-term metabolic adverse effects of clozapine versus other antipsychotics for patients with psychotic illnesses. J Clin Psychopharmacol 34:441-445.

Komossa K, Rummel-Kluge C, Hunger H, Schmid F, Schwarz S, Duggan L, et al. (2010). Olanzapine versus other atypical antipsychotics for schizophrenia. Cochrane Database Syst Rev(3) Cd006654.

Kugathasan P, Horsdal HT, Aagaard J, Jensen SE, Laursen TM, Nielsen RE (2018). Association of secondary preventive cardiovascular treatment after myocardial infarction with mortality among patients with schizophrenia. JAMA Psychiatry 75:1234-1240.

Laursen TM, Munk-Olsen T, Gasse C (2011). Chronic somatic comorbidity and excess mortality due to natural causes in persons with schizophrenia or bipolar affective disorder. Plos One 6:e24597.

Laursen TM, Nordentoft M, Mortensen PB (2014). Excess early mortality in schizophrenia. Annu Rev Clin Psychol 10:425-448.

Leucht S, Cipriani A, Spineli L, Mavridis D, Orey D, Richter F, et al. (2013). Comparative efficacy and tolerability of 15 antipsychotic drugs in schizophrenia: a multiple-treatments meta-analysis. Lancet 382:951-962.

Miller DD (2000). Review and management of clozapine side effects. J Clin Psychiatry 61 (Suppl 8):14-17; discussion 18.

Siskind D, McCartney L, Goldschlager R, Kisely S (2016). Clozapine v. first- and second-generation antipsychotics in treatment-refractory schizophrenia: systematic review and meta-analysis. Br J Psychiatry 209:385-392.

Solmi M, Murru A, Pacchiarotti I, Undurraga J, Veronese N, Fornaro M, et al. (2017). Safety, tolerability, and risks associated with first- and second-generation antipsychotics: a state-of-the-art clinical review. Ther Clin Risk Manag 13:757-777

Souza JS, Kayo M, Tassell I, Martins CB, Elkis H (2013). Efficacy of olanzapine in comparison with clozapine for treatment-resistant schizophrenia: evidence from a systematic review and meta-analyses. CNS Spectr 18:82-89.

Swildens W, Termorshuizen F, de Ridder A, Smeets H, Engelhard IM (2016). Somatic care with a psychotic disorder. Lower somatic health care utilization of patients with a psychotic disorder compared to other patient groups and to controls without a psychiatric diagnosis. Adm Policy Ment Health 43:650-662.

Tiihonen J, Lönnqvist J, Wahlbeck K, Klaukka T, Niskanen L, Tanskanen A, Haukka J (2009). 11-year follow-up of mortality in patients with schizophrenia: a population-based cohort study (FIN11 study). Lancet 374:620-627.

van der Zalm YC, Termorshuizen F, Schulte PF, Bogers JP, Marcelis M, Sommer IE, Selten JP (2018). Prescription and underprescription of clozapine in dutch ambulatory care. Front Psychiatry 9:231.

van der Zalm YC, Termorshuizen F, Selten JP (2019). Concerns about bias in studies on clozapine and mortality. Schizophr Res 204:425-426.

Vanasse A, Blais L, Courteau J, Cohen AA, Roberge P, Larouche A, et al. (2016). Comparative effectiveness and safety of antipsychotic drugs in schizophrenia treatment: a real-world observational study. Acta Psychiatr Scand 134:374-384.

Vermeulen JM, van Rooijen G, van de Kerkhof MPJ, Sutterland AL, Correll CU, de Haan L (2019). Clozapine and long-term mortality risk in patients with schizophrenia: a systematic review and meta-analysis of studies lasting 1.1-12.5 years. Schizophr Bull 45:315-329.

Wimberley T, MacCabe JH, Laursen TM, Sørensen HJ, Astrup A, Horsdal HT, et al. (2017). Mortality and self-harm in association with clozapine in treatment-resistant schizophrenia. Am J Psychiatry 174:990-998. 